\title{
Hepatitis B genotyping: The utility for the clinicians
}

\author{
Gnanadurai John Fletcher ${ }^{1} \cdot$ Chundamannil Eapen Eapen $^{2}$ (D) $\cdot$ Priya Abraham ${ }^{1}$
}

Published online: 15 October 2019

(C) Indian Society of Gastroenterology 2019

\section{Hepatitis B virus (HBV) genome and the origin of genotype}

The HBV belongs to the family Hepadnaviridae. The HBV genome is about 3200 base pairs (bps) in size and is partially double stranded [1]. It is maintained in relaxed circular conformation by cohesive $5^{\prime}$ ends of the deoxy ribonucleic acid (DNA) strands. In addition to the complex and the compact nature of its genome, HBV also displays conspicuous genome economy by the presence of multiple overlapping open reading frames (ORFs) [2].

Unlike other DNA viruses, HBV replication involves a critical reverse transcription step [1]. This step involves ribonucleic acid (RNA)-dependent DNA polymerase, which lacks proofreading activity leading to error-prone viral replication [2]. The rate of nucleotide substitutions per site is about $2.1 \times 10^{-5}$ per year with the mean observation period of 22 years [2]. It is postulated that hepatitis $\mathrm{B}$ e antigen ( $\mathrm{HBe} \mathrm{Ag}$ )-positive carriers are more likely to transmit the virus across human generations. Under such transmission and substitution probabilities, the best conservative extrapolation reveals that HBV would have originated from the most recent common ancestor about 23003100 years ago [2].

The error-prone replication acts as a major molecular factor for the emergence of genotypes and sub-genotypes [3]. Intergenotypic recombination further accentuates the evolution of HBV [3]. As a proof, genotype I is a novel tri-recombinant of genotypes A, C and G [4]. Genotype J shows high similarity with gibbon genotypes and human genotype C [5]. Hence,

Chundamannil Eapen Eapen

eapen@cmcvellore.ac.in

1 Department of Virology, Christian Medical College, Vellore, 632 004, India

2 Department of Hepatology, Christian Medical College, Vellore, 632 004, India evolution of HBV genotypes requires comprehensive molecular investigation to understand its influence on pathogenesis and outcome of HBV infection.

\section{Definition of HBV genotypes}

HBV is classified based on the phylogenetic analyses of the complete viral genome. Degree of nucleotide divergence in the complete genome is a molecular criterion for the designation of genotypes and sub-genotypes [6]. According to standard guidelines, genotypes and sub-genotypes are designated based on $8 \%$ (inter-group) and $4 \%$ to $8 \%$ (inter-genotype) nucleotide divergence respectively [6]. HBV genotype prevalence varies geographically. To date, 10 genotypes, A through $\mathrm{J}$, and 35 sub-genotypes have been identified. The prevalence of genotypes shows geographical restriction: genotype A is prevalent in Africa, India, Europe and America; genotypes B and $\mathrm{C}$ are widely prevalent in Asia-Pacific; genotype $\mathrm{D}$ is prevalent in India, Africa, Mediterranean regions and Europe; genotype $\mathrm{E}$ is widely prevalent in West Africa; genotype F is seen in South and Central Americas; genotype I is largely restricted to Vietnam and Laos; and genotype $\mathrm{J}$ is predominantly seen in Japan $[6,7]$. Studies covering wide geographic regions show the predominance of genotypes A, C and $\mathrm{D}[8,9]$.

\section{How is HBV genotyping done?}

Currently several genotyping methods are available with varying performance characteristics [10]. Most of the methods target the viral DNA due to its relative stability, ubiquity, sensitivity and specificity.

Whole genome sequencing followed by phylogenetic analyses is a gold standard for HBV genotyping, which identifies predominant, novel and recombinant genotypes [11]. The data of the whole genome sequencing can be used for molecular and other in silico applications. 
Inno-LiPA works on the principle of reverse hybridization and is designed to detect known, well-characterized genotypes and mixed genotypes. The analytical sensitivity of this assay varies with viral load: $100 \%$ (1000 intenational units [IU]/ $\mathrm{mL}), 90 \%(100 \mathrm{IU} / \mathrm{mL})$ and $10 \%(\leq 10 \mathrm{IU} / \mathrm{mL})[12]$. Reverse dot blot assay is rapid, inexpensive, accurate and detects mixed genotypes [13]. Oligonucleotide microarray is a sensitive assay, which can detect mixed genotypes; however, it is more expensive than sequencing and real-time polymerase chain reaction (PCR) assays [14].

Polymerase chain reaction-restriction fragment length polymorphism (PCR-RFLP) is a cost-effective method that can be used in large population studies. However, it can yield about $6 \%$ indeterminate results [15]. Restriction fragment mass polymorphism (RFMP) is a highly sensitive assay with the analytical detection limit of 100 copies/mL. It can also detect drug-resistant mutation (YMDD) in the background of wild-type strain. However, it requires matrix-assisted laser desorption/ionization timeof-flight (MALDI-TOF), which is expensive and technically demanding. Occurrence of single nucleotide polymorphisms (SNPs) at restriction sites can yield a spurious band pattern attenuating the sensitivity of the assay [15].

Multiplex PCR is reliable, fast, cost-effective with $93 \%$ accuracy and amenable for large population studies; it can also detect subgenotypes. It can yield $2 \%$ to $5 \%$ indeterminate results and SNPs in primer binding sites can affect the sensitivity [16]. Real-time PCR is rapid, high throughput, and has high sensitivity, less cross-contamination and detects mixed genotypes. SNPs at primer sites affect the sensitivity of the assay [17]. Invader ${ }^{\circledR}$ assay is highly sensitive with the analytical detection limit of 10 copies of DNA/reaction. It can detect mixed genotypes with the ratio of 2-fold difference (predominant genotype: subdominant genotype [1000:10]) [18]. However, sensitivity of the assay is affected by the occurrence of SNPs and deletions in the probe binding sequences.

Serotyping is a non-molecular traditional method used for subtyping. It is simple and inexpensive and amenable to large population studies. The major pitfall of the assay is the generation of indeterminate $(1.4 \%$ to $23.4 \%)$ results. However, it is superior to molecular typing in HBVDNA-negative patients [19].

\section{Broad rationale for HBV genotyping}

HBV infection causes a wide spectrum of liver disease. Acute infection can range from innocuous to life-threatening fulminant disease. Chronic HBV infection can progress from asymptomatic chronic infection to cirrhosis and hepatocellular carcinoma (HCC). HBV is largely non-cytopathic. As a result, immune pathogenesis is invariably determined by intricate interaction between the virus and the host [20]. Several studies consistently showed that HBV genotypes are linked to natural history, pathogenesis and evolution of disease outcomes and influence the efficacy of interferon-based antiviral treatment [21]. Hence, genotyping is essential for comprehensive understanding of the diseases caused by HBV.

\section{Utility of HBV genotyping for the clinician}

\section{Influence of HBV genotypes on the natural history of chronic HBV infection}

Clinicians need reliable and actionable data on HBV genotypes for the successful management of HBV infection. Hence, it is important to first establish the influence of genotypes on the natural history and the outcome of chronic HBV infection.

Studies have attempted to analyze the influence of HBV genotypes on the natural history of chronic HBV infection. These studies have mostly looked at association between the specific HBV genotypes and liver disease severity. A few studies from India reported that genotype D was associated with severe disease compared with genotype A [22, 23]. However, another study revealed no difference in clinical and histological severity between genotypes A and D [24].

In a Taiwanese cohort, genotype $\mathrm{C}$ was associated with higher preponderance of $\mathrm{HBeAg}$-positive chronic infection and reduced spontaneous $\mathrm{HBeAg}$ seroconversion [25]. A Spanish study showed the association between genotype A and durable remission after HBeAg seroconversion [26]. Also, patients infected with genotypes A and B had higher rates of HBsAg seroclearance than genotypes $C$ and D [26]. In Gambia, wild-type genotype E showed propensity for breakthrough infection in vaccinated children, and immune escape mutants were rare in wild-type strain [27]. However, in Taiwanese children, breakthrough infections were predominantly associated with genotypes B and C [28]. Thus, it is reasonable to believe that $\mathrm{HBV}$ genotypes influence or interact with other well-known risk factors in the natural history of chronic HBV infection.

Host immune response plays a substantial role in influencing the outcome of HBV infection [20]. If this assumption is valid, $8 \%$ nucleotide divergence of the complete genome of HBV must be able to exert significant influence on the outcome of HBV infection. Though the outcome of HBV infection is multifactorial, many studies have shown the association between HBV genotypes and various outcomes of HBV infection [21]. The preponderance of genotypes $\mathrm{A}$ and $\mathrm{D}$ with chronic liver disease and the association of genotype $\mathrm{D}$ with more severe liver disease have been shown in Indian population [22]. Another Indian study reported the association between genotype A and severe liver disease as compared to genotype D [29]. Among Japanese patients, genotype A 
$(23 \%)$ was associated with increased viral persistence than non-A genotype (9\%) $(p=0.003)$ [30]. A European study also showed the higher prevalence of genotype $\mathrm{D}$ than genotype $\mathrm{A}$ with acute, self-limited HBV infection ( $80 \%$ vs. $10 \%$, $p<0.01$ ) [31]. In addition, the prevalence of genotype A was higher than genotype $\mathrm{D}$ in patients with chronic infection ( $80 \%$ vs. $11 \%, p<0.1$ ) [31]. In the context of HBV mutants, genotypes $\mathrm{C}$ and $\mathrm{D}$ have a higher frequency of basal core promoter A1762T/G1764A mutations than genotypes A and B. HBV genotypes C, D and F carry a higher lifetime risk of cirrhosis and HCC development than genotypes A and B. $\mathrm{HBV}$ pre-S/S gene mutations were associated with immune escape of hepatitis B immunoglobulin or vaccine-induced immunity. Mutations in the pre-S, core promoter and $\mathrm{X}$ regions correlated with an increased risk of cirrhosis and HCC [32].

Taking the available evidence into consideration, it is logical to suggest that the $8 \%$ nucleotide divergence leading to genotype difference in HBV may translate into variation of immunodominant epitopes presented on the hepatocytes affecting the immunopathogenesis of the disease and the outcome.

\section{Influence of HBV genotypes on HCC development}

As multiple studies clarified the influence of HBV genotypes on the natural history and the outcome of HBV infection, it is likely that certain genotypes may increase the risk of HCC development. A study from north-eastern India showed predominance of genotype $\mathrm{D}$ followed by similar prevalence of genotypes $\mathrm{A}$ and $\mathrm{C}$ in $\mathrm{HCC}$ patients [33]. Another Indian study also reported the role of genotype $\mathrm{D}$ (odds ratio, OR = 1.8 ) and mixed genotypes (odds ratio, $\mathrm{OR}=6.9$ ) and higher viral load in HCC risk [34].

Most patients who develop HCC in India have cirrhosis and hepatitis B infection. The lower incidence of HCC in patients with cirrhosis in India compared with other countries is considered an enigma [35]. Whether viral factors like HBV genotype have any role in explaining this enigma needs to be studied.

A few other studies have shown the association between genotype $\mathrm{C}$ infection and higher risk of cirrhosis and $\mathrm{HCC}$ as compared to genotype B. Notably, a large community-based Taiwanese cohort study showed an association between genotype $\mathrm{C}$ and higher risk of $\mathrm{HCC}$ as compared to genotype $\mathrm{B}$ (adjusted hazard ratio [HR] 2.4 [CI 1.7-3.3], $p<0.001$ ) [36]. The higher prevalence of HCC with genotype $\mathrm{C}$ was directly linked to higher viral load. In particular, patients infected with genotype $\mathrm{C}$ with higher viral load had 26-folds higher risk of HCC than other genotypes [37]. Furthermore, Tseng et al. (2012) on a cohort of 2688 Taiwanese patients showed an association between HCC incidence and genotype $\mathrm{C}$ than genotype B [38]. In addition, a few studies have elucidated the association of genotype B with HCC risk in younger age and genotype $\mathrm{C}$ with $\mathrm{HCC}$ risk in the older age [21]. Alaskan natives with genotype $\mathrm{F}$ had significantly increased the risk of HCC development than genotypes $\mathrm{A}-\mathrm{D}(\mathrm{OR}=7.73, \mathrm{CI}$ 3.69-16.4, $p<0.001$ ) [39].

The incidence of HCC during long-term follow up in patients infected with different HBV genotypes has been studied in Japan. In a recent study of patients chronically infected with HBV, HCC incidence was $13.4 \%$ at 10 years. In these patients, the incidence of HCC was lower in genotype B $(5.3 \%$ at 10 years) than in genotype $\mathrm{C}(18.5 \%$ at 10 years) [40]. Another recent study from Japan recorded higher incidence of HCC in genotype B patients compared with genotype $\mathrm{C}$ during the first 20 years of follow up; however, the HCC incidence was similar in genotypes B and C, after 20 years [41].

A nomogram to predict the risk of developing HCC in an individual who is infected with hepatitis B was developed using the REVEAL study database; it was shown to be accurate in predicting $\mathrm{HCC}$ development in the validation cohort. HBV genotype was one of the 8 predictive risk factors used in this nomogram. This information (ability to predict risk of HCC) may be useful to counsel patients with hepatitis B and may help clinical decision-making about starting anti-viral treatment [42]. However, as this was developed and validated in the REVEAL study from Taiwan (predominant HBV genotypes B and C), this may not be applicable to other parts of the world [43]. Similar scores/nomograms to predict risk of HCC need to be developed in other countries, incorporating HBV genotype data prevalent in the population of the region studied.

Studies have also analyzed HBV sub-genotypes and its association with $\mathrm{HCC}$. Recent reports suggest that $\mathrm{HBV}$ sub-genotype D1 may have higher potential to cause HCC than D3 [44].

\section{Influence of HBV genotype on development of acute-on-chronic liver failure}

Cross-sectional studies from China suggest that patients with HBV genotype B and having mutations in basal core promoter and pre-core/core regions of the HBV gene had higher predisposition to develop acute-on-chronic liver failure (ACLF) compared with the patients with HBV genotype $\mathrm{C}$ and wildtype basal core promoter and pre-core/core regions of the HBV gene $[45,46]$.

\section{Influence of HBV genotypes on the outcome of antiviral treatment}

Current guidelines recommend two therapeutic options for chronic HBV infection that include standard/pegylated interferon (PEG-IFN) and nucleos(t)ide analogues. Many reports point towards the definite impact of HBV genotypes on interferon-based therapies $[15,47]$. In contrast, response to 
nucleos(t)ide analogues is not significantly influenced by HBV genotype [47].

\section{HBV genotypes and response to interferon therapy}

Host immune response plays an important role in the pathogenesis and outcome of chronic HBV infection. Interferon stimulates multiple antiviral pathways of the host. HBV genotypes may differentially influence the virus-host interaction. Several studies have shown the influence of HBV genotypes on the outcome of IFN therapy [15, 21].

IFN treatment in HBeAg-positive patients led to higher rates of $\mathrm{HBeAg}$ seroconversion in patients with genotypes $\mathrm{A}$ and $\mathrm{B}$ than those with genotypes $\mathrm{C}$ and $\mathrm{D}[48,49]$. A multicentre study revealed that in HBeAg-positive patients, PEGIFN treatment had varying rate of $\mathrm{HBeAg}$ clearance among HBV genotypes: A (47\%), B (44\%), C (28\%) and D (25\%) [50]. On further analysis, patients with genotype A had higher rates of HBsAg clearance irrespective of their $\mathrm{HBeAg}$ status [51]. Confirming these findings, a meta-analysis showed that genotype A was associated with greater response to IFN therapy than genotype D irrespective of $\mathrm{HBeAg}$ status [47]. Furthermore, in HBeAg-positive patients, genotype $\mathrm{C}$ predicted poorer response to IFN therapy than genotype B [47].

During PEG-IFN therapy, in HBeAg-positive patients with genotypes B and C, HBsAg levels at week $12(<1500 \mathrm{IU} / \mathrm{mL})$ correlated with $\mathrm{HBeAg}$ seroconversion. On the contrary, patients with high HBsAg levels at week 12 (>20,000 IU/mL) were refractory to therapy [52]. Likewise, during PEG-IFN therapy, in $\mathrm{HBeAg}$-positive patients infected with genotypes $\mathrm{A}$ and $\mathrm{D}$, lack of change in HBsAg levels demonstrated inferior response in the form of $\mathrm{HBeAg}$ loss at 26 weeks after treatment [53]. In HBeAg-negative patients, the response to PEG-IFN therapy varied widely with genotypes, which can be largely categorized based on the mean reduction of HBsAg level: highest response with genotype $\mathrm{A}$, intermediate with genotypes $\mathrm{B}$ and $\mathrm{D}$ and lowest with genotypes $\mathrm{C}$ and $\mathrm{E}$. However, on further follow up, genotypes A and D showed sustained decrease and genotypes B, C and E showed variable rebound [54].

\section{HBV genotypes and response to nucleos(t)ide analogues}

The response to nucleos(t)ide analogue therapy is largely similar among various HBV genotypes [47]. A few studies have shown the preponderance of genotype $\mathrm{B}$ among patients with earlier emergence and establishment of lamivudine resistance [21]. However, another study contradicted and showed the sustained responsiveness to lamivudine with genotype $\mathrm{B}$ than genotype $C$ [55]. In vitro studies showed that wild-type HBV strains (genotypes A-H) and drug-resistant hepatitis B strains were susceptible to tenofovir alafenamide [56]. In chronically HBV-infected patients treated with different nucleos(t)ide analogues-lamivudine, entecavir, tenofovir (disoproxil fumarate or alafenamide fumarate) - for $>6$ months (mean duration of treatment 71 months), patients with genotype $B$ had a significantly higher cumulative rate of $\mathrm{HBsAg}$ loss $(3.6 \%$ at 10 years) than those with genotype $\mathrm{C}(0.7 \%$ at 10 years $)$ [40].

In patients who are on nucleos $(\mathrm{t})$ ide therapy for prolonged periods, HBV genotype may switch from one to another, probably due to treatment-induced pressure. Genotype A and mixed genotypes were more likely to switch, while the patients were treated with tenofovir, compared with genotype D [57].

\section{Public health importance of HBV genotyping data}

HBV genotypes and sub-genotypes have distinct geographical distribution. Immigration has recently become an important confounding factor of global HBV distribution and has been substantially changing the geographic pattern of HBV subgenotypes. Inter-genotype recombination can further contribute to the virus's evolutionary history. The circulation of novel recombinants and variants justifies the need to improve immune prophylaxis, diagnosis and treatment strategies.

HBV genotyping is an important tool that has been used to investigate the cause of outbreaks of hepatitis B [58] and modes of transmission [59]. When outbreaks of hepatitis B are observed as well as when newer modes of HBV transmission (for example HBV transmission via insects) are hypothesized [60], tools like HBV genotyping are likely to be useful in investigating these.

\section{Conclusions}

Whole genome sequencing is still the preferred and gold standard method of HBV genotyping. Globally, evidence suggests that HBV genotypes influence the natural history, pathogenesis and outcomes of the infection. In particular, genotypes $\mathrm{C}$ and $\mathrm{D}$ significantly increase the risk of progression to cirrhosis and HCC development as compared with genotypes A and B. While HBV genotypes influence response to IFN therapy, they do not appear to significantly impact response to nucleos(t)ide therapy. Routine HBV genotyping as part of clinical practice is not warranted at present.

The HBV genotype landscape in India, with its multiethnic population, is likely to be diverse. Many reports from India have documented HBV genotypes in infected individuals in specific regions of the country [61-72]. In this context, a panIndian study on the regional variations in HBV genotypes in this issue of the Journal is laudable [73]. More studies in this field are needed to unravel the transmission and pathogenic mechanisms of hepatitis B and its potential implications for prevention and treatment. 


\section{Compliance with Ethical Standards}

Conflict of Interest GJF, CEE, and PA declare that they have no conflict of interest.

Disclaimer The authors are solely responsible for the data and the contents of the paper. In no way, the Honorary Editor-in-Chief, Editorial Board Members, or the printer/publishers are responsible for the results/ findings and content of this article.

\section{References}

1. Seeger C, Mason WS. Molecular biology of hepatitis B virus infection. Virology. 2015;479-480:672-86.

2. Simmonds P. The origin and evolution of hepatitis viruses in humans. J Gen Virol. 2001;82 (Pt 4) :693-712.

3. Lin CL, Kao JH. Hepatitis B virus genotypes and variants. Cold Spring Harb Perspect Med. 2015;5:a021436.

4. Tran TT, Trinh TN, Abe K. New complex recombinant genotype of hepatitis B virus identified in Vietnam. J Virol. 2008;82:5657-63.

5. Tatematsu K, Tanaka Y, Kurbanov F, et al. A genetic variant of hepatitis $\mathrm{B}$ virus divergent from known human and ape genotypes isolated from a Japanese patient and provisionally assigned to new genotype J. J Virol. 2009;83:10538-47.

6. Schaefer S. Hepatitis B virus taxonomy and hepatitis B virus genotypes. World J Gastroenterol. 2007;13:14-21.

7. Kramvis A. Genotypes and genetic variability of hepatitis B virus. Intervirology. 2014;57:141-50.

8. Ismail AM, Puhazhenthi KS, Sivakumar J, et al. Molecular epidemiology and genetic characterization of hepatitis B virus in the Indian subcontinent. Int J Infect Dis. 2014;20:1-10.

9. Ismail AM, Goel A, Kannangai R, Abraham P. Further evidence of hepatitis B virus genotype I circulation in Northeast India. Infect Genet Evol. 2013;18:60-5.

10. Bartholomeusz A, Schaefer S. Hepatitis B virus genotypes: comparison of genotyping methods. Rev Med Virol. 2004;14:3-16.

11. Valsamakis A. Molecular testing in the diagnosis and management of chronic hepatitis B. Clin Microbiol Rev. 2007;20:426-39.

12. Qutub MO, Germer JJ, Rebers SP, et al. Simplified PCR protocols for INNO-LiPA HBV genotyping and INNO-LiPA HBV precore assays. J Clin Virol. 2006;37:218-21.

13. Zhang R, Deng Y, Muller CP, et al. Determination of hepatitis B virus genotype by flow-through reverse dot blot. J Clin Virol. 2007;39:94-100.

14. Wang YZ, Wu GX, Luo LB, et al. Oligonucleotide chip, real-time PCR and sequencing for genotyping of hepatitis B virus. World J Gastroenterol. 2007;13:4260-3.

15. Guirgis BS, Abbas RO, Azzazy HM. Hepatitis B virus genotyping: current methods and clinical implications. Int J Infect Dis. 2010;14: e941-53.

16. Liu WC, Lindh M, Buti M, et al. Genotyping of hepatitis B virusgenotypes a to $\mathrm{g}$ by multiplex polymerase chain reaction. Intervirology. 2008;51:247-52.

17. Liu WC, Mizokami M, Buti M, et al. Simultaneous quantification and genotyping of hepatitis B virus for genotypes A to $\mathrm{G}$ by realtime PCR and two-step melting curve analysis. J Clin Microbiol. 2006;44:4491-7.

18. Tadokoro K, Kobayashi M, Yamaguchi T, et al. Classification of hepatitis B virus genotypes by the PCR-invader method with genotype-specific probes. J Virol Methods. 2006;138:30-9.

19. Usuda S, Okamoto H, Iwanari H, et al. Serological detection of hepatitis B virus genotypes by ELISA with monoclonal antibodies to type-specific epitopes in the preS2-region product. J Virol Methods. 1999;80:97-112.

20. Ganem D, Prince AM. Hepatitis B virus infection - natural history and clinical consequences. N Engl J Med. 2004;350:1118-29.

21. Lin CL, Kao JH. Hepatitis B virus genotypes and variants. Cold Spring Harb Perspect Med. 2015;5:a021436.

22. Thakur V, Guptan RC, Kazim SN, et al. Profile, spectrum and significance of HBV genotypes in chronic liver disease patients in the Indian subcontinent. J Gastroenterol Hepatol. 2002;17:165-70.

23. Kumar A, Dwivedi M, Misra SP, et al. Distribution of hepatitis B virus genotypes and its association with severity of liver disease in patients with chronic hepatitis B in Uttar Pradesh, India. Indian J Virol. 2011;22:24-8.

24. Madan K, Batra Y, Sreenivas V, et al. HBV genotypes in India: do they influence disease severity? Hepatol Res. 2009;39:157-63.

25. Kao JH, Chen PJ, Lai MY, Chen DS. Genotypes and clinical phenotypes of hepatitis B virus in patients with chronic hepatitis B virus infection. J Clin Microbiol. 2002;40:1207-9.

26. Sánchez-Tapias JM, Costa J, Mas A, et al. Influence of hepatitis B virus genotype on the long-term outcome of chronic hepatitis B in western patients. Gastroenterology. 2002;123:1848-56.

27. Mendy M, D'Mello F, Kanellos T, et al. Envelope protein variability among HBV-infected asymptomatic carriers and immunized children with breakthrough infections. J Med Virol. 2008;80: 1537-46.

28. Chang $\mathrm{MH}$. Breakthrough $\mathrm{HBV}$ infection in vaccinated children in Taiwan: surveillance for HBV mutants. Antivir Ther. 2010;15 (3 Pt B) :463-9.

29. Kumar A, Kumar SI, Pandey R, et al. Hepatitis B virus genotype A is more often associated with severe liver disease in northern India than is genotype D. Indian J Gastroenterol. 2005;24:19-22.

30. Ito K, Yotsuyanagi H, Yatsuhashi H, et al. Japanese AHB Study Group. Risk factors for long-term persistence of serum hepatitis B surface antigen following acute hepatitis B virus infection in Japanese adults. Hepatology. 2014;59:89-97.

31. Mayerat C, Mantegani A, Frei PC. Does hepatitis B virus (HBV) genotype influence the clinical outcome of HBV infection? J Viral Hepat. 1999;6:299-304.

32. Lin CL, Kao JH. Natural history of acute and chronic hepatitis B: the role of HBV. genotypes and mutants. Best Pract Res Clin Gastroenterol. 2017;31:249-55.

33. Sarma MP, Bhattacharjee M, Kar P, Medhi S. Detection of HBV genotype $\mathrm{C}$ in hepatocellular carcinoma patients from North East India: a brief report. Asian Pac J Cancer Prev. 2018;19:1741-6.

34. Asim M, Sarma MP, Kar P. Etiological and molecular profile of hepatocellular cancer from India. Int J Cancer. 2013;133:437-45.

35. Mohandas KM. Surveillance of Indians with liver cirrhosis for treatable hepatocellular carcinoma: another enigma. Indian J Gastroenterol. 2007;26:261-4.

36. Yang HI, Yeh SH, Chen PJ, et al. Associations between hepatitis B virus genotype and mutants and the risk of hepatocellular carcinoma. J Natl Cancer Inst. 2008;100:1134-43.

37. Yu MW, Yeh SH, Chen PJ, et al. Hepatitis B virus genotype and DNA level and hepatocellular carcinoma: a prospective study in men. J Natl Cancer Inst. 2005;97:265-72.

38. Tseng TC, Liu CJ, Yang HC, et al. High levels of hepatitis B surface antigen increase risk of hepatocellular carcinoma in patients with low HBV load. Gastroenterology. 2012;142:1140-9.

39. Livingston SE, Simonetti JP, McMahon BJ, et al. Hepatitis B virus genotypes in Alaska native people with hepatocellular carcinoma: preponderance of genotype F. J Infect Dis. 2007;195:5-11.

40. Inoue J, Akahane $\mathrm{T}$, Nakayama $\mathrm{H}$, et al. Comparison of hepatitis $\mathrm{B}$ virus genotypes $\mathrm{B}$ and $\mathrm{C}$ among chronically hepatitis $\mathrm{B}$ virusinfected patients who received nucleos(t)ide analogs: a multicenter retrospective study. Hepatol Res. 2019. https://doi.org/10.1111/ hepr.13398. 
41. Haga H, Saito T, Okumoto K, et al. Incidence of development of hepatocellular carcinoma in Japanese patients infected with hepatitis $\mathrm{B}$ virus is equivalent between genotype $\mathrm{B}$ and $\mathrm{C}$ in long term. $\mathrm{J}$ Viral Hepat. 2019;26:866-72.

42. Yang HI, Sherman M, Su J, et al. Nomograms for risk of hepatocellular carcinoma in patients with chronic hepatitis B virus infection. J Clin Oncol. 2010;28:2437-44.

43. Colombo M, Sirlin CB. Surveillance for hepatocellular carcinoma in adults. https://www.uptodate.com/contents/surveillance-forhepatocellular-carcinoma-in-adults. Accessed 25 Aug 2019.

44. Datta S, Dasgupta D, Ghosh A, et al. Oncogenic potential of hepatitis B virus subgenotype D1 surpasses D3: significance in the development of hepatocellular carcinoma. Carcinogenesis. 2018;39:283-92.

45. Ren X, Xu Z, Liu Y, et al. Hepatitis B virus genotype and basal core promoter / precore mutations are associated with hepatitis B-related acute-on-chronic liver failure without pre-existing liver cirrhosis. J Viral Hepat. 2010;17:887-95.

46. Yang G, Han M, Chen F, et al. Hepatitis B virus genotype B and mutations in basal core promoter and pre-core/core genes associated with acute-on-chronic liver failure: a multicenter cross-sectional study in China. Hepatol Int. 2014;8:508-16.

47. Wiegand J, Hasenclever D, Tillmann HL. Should treatment of hepatitis B depend on hepatitis B virus genotypes? A hypothesis generated from an explorative analysis of published evidence. Antivir Ther. 2008;13:211-20.

48. Kao JH, Wu NH, Chen PJ, et al. Hepatitis B genotypes and the response to interferon therapy. J Hepatol. 2000;33:998-1002.

49. Wai CT, Chu CJ, Hussain M, Lok AS. HBV genotype B is associated with better response to interferon therapy in $\mathrm{HBeAg}(+)$ chronic hepatitis than genotype C. Hepatology. 2002;36:1425-30.

50. Janssen HL, van Zonneveld M, Senturk H, et al. Pegylated interferon $\alpha-2 b$ alone or in combination with lamivudine for HBeAgpositive chronic hepatitis B: a randomised trial. Lancet. 2005;365: 123-9.

51. Flink HJ, van Zonneveld M, Hansen BE, et al. Treatment with Peginterferon alpha-2b for $\mathrm{HBeAg}$-positive chronic hepatitis B: HBsAg loss is associated with HBV genotype. Am J Gastroenterol. 2006;101:297-303.

52. Sonneveld MJ, Hansen BE, Piratvisuth T, et al. Response-guided peginterferon therapy in hepatitis $\mathrm{B}$ e antigen-positive chronic hepatitis B using serum hepatitis B surface antigen levels. Hepatology. 2013;58:872-80

53. Sonneveld MJ, Rijckborst V, Boucher CA, et al. Prediction of sustained response to peginterferon alfa- $2 b$ for hepatitis $B$ e antigen-positive chronic hepatitis B using on-treatment hepatitis B surface antigen decline. Hepatology. 2010;52:1251-7.

54. Moucari R, Martinot-Peignoux M, Mackiewicz V, et al. Influence of genotype on hepatitis B surface antigen kinetics in hepatitis B e antigen-negative patients treated with pegylated interferon-alpha2a. Antivir Ther. 2009;14:1183-8.

55. Hsieh TH, Tseng TC, Liu CJ, et al. Hepatitis B virus genotype B has an earlier emergence of lamivudine resistance than genotype $\mathrm{C}$. Antivir Ther. 2009;14:1157-63.

56. Liu Y, Miller MD, Kitrinos KM. Tenofovir alafenamide demonstrates broad cross-genotype activity against wild-type HBV clinical isolates and maintains susceptibility to drug-resistant HBV isolates in vitro. Antivir Res. 2017;139:25-31.

57. Chauhan R, Singh AK, Rooge S, et al. Analysis of hepatitis B virus genotype changes in patients with chronic hepatitis B infection on tenofovir therapy. J Med Virol. 2016;88:1364-75.
58. Arankalle VA, Gandhi S, Lole KS, et al. An outbreak of hepatitis B with high mortality in India: association with precore, basal core promoter mutants and improperly sterilized syringes. J Viral Hepat. 2011;18:e20-8.

59. Ismail AM, Raghavendran A, Sivakumar J, et al. Mother to child transmission of hepatitis B virus: a cause for concern. Indian J Med Microbiol. 2015;33 Suppl:140-3.

60. Kuriakose M, Ittyachen AM. An investigation into the high prevalence of hepatitis B in a rural area of Kerala state, India: hypothesis on Chrysops sp. (Diptera: Tabanidae) transmission. Biomed Res Int. 2018:4612472.

61. Sharma B, Katiyar H, Barall D, et al. Genotyping of hepatitis B virus isolates from Lahaul and Spiti district in Himachal Pradesh, India. Indian J Gastroenterol. 2018;37:261-5.

62. Khan MA, Zargar SA, Upadhyay J, et al. Epidemiology of hepatitis $\mathrm{B}$ and $\mathrm{C}$ viral infections in Ladakh region. Indian J Gastroenterol. 2018;37:504-10.

63. Vivekanandan P, Bissett S, Ijaz S, et al. Correlation between hepatitis B genotypes, 1896 precore mutation, virus loads and liver dysfunction in an Indian population. Indian J Gastroenterol. 2008;27:142-7.

64. Gopalakrishnan D, Keyter M, Shenoy KT, et al. Hepatitis B virus subgenotype A1 predominates in liver disease patients from Kerala, India. World J Gastroenterol. 2013;19:9294-306.

65. Agarwal AK, Sen S, Banerjee D, et al. Distribution of hepatitis B virus genotype and cancer predicting precore and basal core promoter mutations. Med J Armed Forces India. 2015;71: 225-32.

66. Bhattacharya H, Bhattacharya D, Ghosal SR, et al. Status of hepatitis B infection - a decade after hepatitis B vaccination of susceptible Nicobarese, an indigenous tribe of Andaman \& Nicobar $(\mathrm{A} \& \mathrm{~N})$ islands with high hepatitis B endemicity. Indian J Med Res. 2015;141:653-61.

67. Saikia A, Bose M, Barman NN, et al. Molecular epidemiology of HBV infection in chronic hepatitis B virus infected patients in northeast India. J Med Virol. 2015;87:1539-48.

68. Dwibedi B, Sabat J, Ho LM, et al. Molecular epidemiology of hepatitis B virus in primitive tribes of Odisha, eastern India. Pathog Glob Health. 2014;108:362-8.

69. Haldipur BP, Walimbe AM, Arankalle VA. Circulation of genotype-I hepatitis B virus in the primitive tribes of Arunachal Pradesh in early sixties and molecular evolution of genotype-I. Infect Genet Evol. 2014;27:366-74.

70. Tuteja A, Siddiqui AB, Madan K, et al. Mutation profiling of the hepatitis B virus strains circulating in North Indian population. PLoS One. 2014;9:e91150.

71. Gandhe SS, Chadha MS, Arankalle VA. Hepatitis B virus genotypes and serotypes in western India: lack of clinical significance. J Med Virol. 2003;69:324-30.

72. Koli S, Pallipurath Radhakrishnan AN, Jacob M, et al. Occurrence of hepatitis B virus genotype $\mathrm{B}$ and $\mathrm{B}+\mathrm{C}$ mixed infections in Chennai, South India. Braz J Infect Dis. 2013;17:615-6.

73. Rao PN, Shah SR, Chowdhury A, et al. Chronic hepatitis B virus infection in India: regional demographics and distribution of viral genotypes. Indian J Gastroenterol. 2019;38. https://doi.org/10. 1007/s12664-019-00961-8.

Publisher's note Springer Nature remains neutral with regard to jurisdictional claims in published maps and institutional affiliations. 